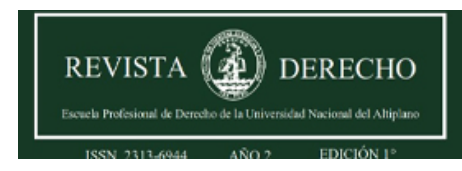

Revista de Derecho

ISSN: 2313-6944

ISSN: 2707-9651

revistaderecho@unap.edu.pe

Universidad Nacional del Altiplano

Perú

\title{
JUSTICIA COMUNITARIA: LA NECESIDAD DE LA IMPLEMENTACIÓN DE LA LEY DE COORDINACIÓN JURISDICCIONAL
}

Hancco Aguilar, Willian Alain

JUSTICIA COMUNITARIA: LA NECESIDAD DE LA IMPLEMENTACIÓN DE LA LEY DE COORDINACIÓN JURISDICCIONAL

Revista de Derecho, vol. 5, núm. 2, 2020

Universidad Nacional del Altiplano, Perú

Disponible en: https://www.redalyc.org/articulo.oa?id=671870937013

DOl: https://doi.org/10.47712/rd.2020.v5i2.91

\section{(c) (7)}

Esta obra está bajo una Licencia Creative Commons Atribución 4.0 Internacional. 


\section{JUSTICIA COMUNITARIA: LA NECESIDAD DE LA IMPLEMENTACIÓN DE LA LEY DE COORDINACIÓN JURISDICCIONAL}

\section{Community justice: the need for the implementation of the jurisdictional coordination law}

Willian Alain Hancco Aguilar*

Ministerio Publico, Perú

\author{
DOI: https://doi.org/10.47712/rd.2020.v5i2.91 \\ Redalyc: https://www.redalyc.org/articulo.oa? \\ id $=671870937013$ \\ Recepción: 30 Septiembre 2020 \\ Aprobación: 25 Octubre 2020 \\ Publicación: 27 Octubre 2020
}

\section{RESUMEN:}

La "justicia comunal”, es una forma de solución de conflictos de carácter conciliatorio en comunidades campesinas y nativas que reconoce nuestro sistema de justicia en el Perú, pues en el artículo $149^{\circ}$ de la Constitución establece que las autoridades de las Comunidades Campesinas y Nativas, con el apoyo de las Rondas Campesinas, pueden ejercer las funciones jurisdiccionales dentro de su ámbito territorial de conformidad con el derecho consuetudinario, siempre que no violen los derechos fundamentales de la persona; sin embargo este articulo al no tener una "Ley de coordinación jurisdiccional entre la justicia ordinaria y la justicia comunitaria" que reglamente su aplicación ha venido siendo utilizada de manera inadecuada y en muchas veces con abuso de derecho por las Rondas campesinas a nivel nacional y de manera muy específica se recoge las actuaciones de las Rondas Campesinas del distrito de Macusani provincia de Carabaya de la Región Puno, pues ellos de forma errada invocando y amparándose en el Artículo $149^{\circ}$ de la constitución creen tener jurisdicción y competencia para administrar justicia en un Distrito urbano como es Macusani, ciudad donde existe presencia del Estado a fin de administrar Justicia ordinaria, por ende es necesaria la implementación en nuestro sistema jurídico la "Ley de coordinación jurisdiccional entre la justicia ordinaria y la justicia comunitaria".

Palabras clave: Administración de Justicia, Jurisdicción, competencia, solución de conflictos, Rondas Campesinas, Ley de Coordinación jurisdiccional.

\section{Abstract:}

The "communal justice" is a way of solving conflicts of a conciliatory nature in peasant and native communities that our justice system in Peru recognizes, because in article 149 of the Constitution it establishes that the authorities of the Peasant and Native Communities With the support of the Rondas Campesinas, they can exercise jurisdictional functions within their territorial scope in accordance with customary law, provided that they do not violate the fundamental rights of the person; However, this article, as it does not have a "Law of jurisdictional coordination between ordinary justice and community justice" that regulates its application has been used in an inappropriate way and in many times with abuse of rights by the peasant Rondas at the national and In a very specific way, the actions of the Rondas Campesinas of the district of Macusani province of Carabaya of the Puno Region are collected, since they mistakenly invoking and taking refuge in Article 149 of the constitution believe they have jurisdiction and competence to administer justice in a District urban such as Macusani, a city where there is a presence of the State in order to administer ordinary Justice, therefore it is necessary to implement in our legal system the "Law of jurisdictional coordination between ordinary justice and community justice."

KEYWORDS: Administration of Justice, Jurisdiction, competition, conflict resolution, Peasant Rounds, Jurisdictional Coordination Law.

\section{NotAS DE AUTOR}

* Abogado por la Universidad Nacional del Altiplano-Puno, Asistente en Función Fiscal de la Fiscalía Superior Mixta de Huancané - Ministerio Publico, con estudios concluidos en Maestría en Derecho - mención Derecho Constitucional y Derechos Humanos de la Escuela de Posgrado de la Universidad Nacional del Altiplano y actualmente cursando estudios de Doctorado en Derecho en la Escuela de Posgrado de la Universidad Nacional del Altiplano. 


\section{I.- INTRODUCCIÓN}

El Perú en su Constitución Política reconoce la "Justicia comunitaria", y lo regula en su artículo $149^{\circ}$; sin embargo este mismo artículo no tiene un reglamento o ley de coordinación jurisdiccional en donde especifique los limites en cuanto a competencias y procedimientos que deben utilizar las autoridades comunales y con apoyo de las Rondas Campesinas, sino es una norma abierta y genérica, si bien se tiene conocimiento de que la Ley de coordinación jurisdiccional entre la Justicia ordinaria con la justicia comunitaria, ya se encontraba en el Congreso de la Republica hace un tiempo atrás; sin embargo no ha prosperado la misma a fin de promulgarse y de una vez por todas armonizar la Justicia ordinaria con la justicia comunitaria. Al encontrarse principios y parámetros establecidos para una recta participación de las Rondas Campesinas a nivel nacional en muchas ocasiones los miembros de las Rondas Campesinas envistiéndose de jurisdicción realizan actos de investigación vulnerando derechos fundamentales como a la integridad física, la libertad, el derecho a la defensa entre otros derechos, esto porque nuestra legislación no reglamenta en cuanto a procedimientos y límites de dicha jurisdicción especial que regula el artículo $149^{\circ}$; si bien existe el Acuerdo Plenario $\mathrm{N}^{\circ} 1-2009 / \mathrm{Cj}-116$; sin embargo en esta jurisprudencia tan solo fija conceptos y establece algunos lineamientos de las actuaciones de las Rondas Campesinas, empero no podría remplazar a una Ley de Coordinación jurisdiccional.

En el presente artículo se ha tomado como base la intervención y actuación de las Rondas Campesinas del distrito de Macusani en la Provincia de Carabaya, donde ocurre un caso sui generis pues las Rondas Campesinas en el año 2015 y 2016 al momento de su actuación no realizan apoyo a las autoridades de las comunidades campesinas como les faculta el precepto constitucional, sino se envisten ellos de jurisdicción y actúan dentro del radio urbano es decir tienen su intromisión en la Administración de Justicia ordinaria dentro de la ciudad de Macusani, ciudad donde existen las sedes del Poder Judicial y el Ministerio Público, si bien no tiene nada irregular que ellos coadyuven con investigaciones para determinar responsables de algún delito; sin embargo el asunto va más allá cuando estas organizaciones al momento de actuar vulneran derechos fundamentales utilizando en varios casos la tortura y otro tipo de maltratos para obtener confesiones además que actúan fuera de su jurisdicción para la que se constituyeron es decir actúan en un medio urbano y no en un medio rural; entonces son este tipo de actuaciones y funcionamiento que hacen imperiosa la necesidad de que exista una ley de coordinación jurisdiccional que establezca lineamientos y parámetros para las actuación de las autoridades de las Comunidades Campesinas con apoyo de las Rondas Campesinas.

\section{II.- CONTENIDO}

\section{1.- La justicia comunitaria y el respeto de los derechos fundamentales}

La justicia comunitaria o justicia comunal tiene su regulación en nuestro sistema jurídico en el Artículo $149^{\circ}$ de la Constitución Política en la misma preceptúa que "Las autoridades de las Comunidades Campesinas y Nativas, con el apoyo de las Rondas Campesinas, pueden ejercer las funciones jurisdiccionales dentro de su ámbito territorial de conformidad con el derecho consuetudinario, siempre que no violen los derechos fundamentales de la persona. La ley establece las formas de coordinación de dicha jurisdicción especial con los Juzgados de Paz y con las demás instancias del Poder Judicial”; de la lectura del precepto legal citado se colige que las Rondas Campesinas no cuentan con funciones jurisdiccionales sino que deben apoyar a las autoridades de las Comunidades Campesinas o Nativas en dicha función, es decir quien tiene facultad para ejercer funciones jurisdiccionales son las autoridades de las comunidades campesinas y, las rondas campesinas realizan apoyo en dicha función; de igual manera en el mencionado precepto constitucional señala que deben actuar dentro de un medio rural (Comunidades Campesinas o Nativas), entonces considerando esta norma Constitucional debemos verificar las actuaciones y desenvolvimiento que efectúan las Rondas Campesinas de manera general a nivel nacional. 


\section{2.- Actuaciones de las rondas campesinas.-}

Se verifica las actuaciones de las Rondas Campesinas de manera general a nivel nacional, a través de los medios de comunicación y de forma específica se analiza las actuaciones de las Rondas Campesinas del Distrito de Macusani, para el mismo se plantea dos casos que tuvieron su suceso en el año 2015 y 2016 donde en ambas situaciones que se trataba de procesos penales por el delito de homicidio, las Rondas Campesinas al detener a los presuntos homicidas efectuaron una serie de actuaciones que contravienen a sus derechos fundamentales tales como lesiones a su integridad física hasta atentado contra sus vidas, estas actuaciones se aseveran toda vez que estos presuntos homicidas denunciaron a nivel de la Fiscalía Provincial Penal de Carabaya a varios dirigentes y miembros de las Rondas Campesinas por los delitos de tortura, secuestro y coacción indicando que fueron víctimas de lesiones a su integridad física por parte de varios miembros y dirigentes de las Rondas Campesinas vulnerando así sus derechos fundamentales reconocidos por la Ley.

Para mejor ilustración se tiene extractos de sus manifestaciones a nivel fiscal de los presuntos homicidas que en dicha investigación tienen la calidad de denunciantes a los que llamaremos solo con la denominación "denunciante 1" y "denunciante 2" y a los miembros y dirigentes de las Rondas campesinas denunciados con la denominación "Rondero 1, Rondero 2, así sucesivamente"; esto a fin de protección de datos personales y a su vez a fin de no interferir en dicha investigación fiscal y judicial, en ese tenor se tiene la declaración a nivel fiscal del "denunciante 1", que indica: “(...) a la pregunta: ¿cuál sería la participación de cada una de las personas que ha denunciado por los delitos de secuestro, tortura y coacción? (...)” respondió: "La persona de "Rondero 1", me ha golpeado en los pies con palo, en el local de Barrio de Héroes del Cenepa de Macusani y me agarraba con soga y en compañía de los demás roderos, y me metía la cabeza a un cilindro de agua con detergente, así también ordenaba que me envolvieran las señoras con ortigas en todo mi cuerpo cuando estaba desnudo, eso paso solo una oportunidad en un día; (...) respecto a las personas de "Rondero 2", "Rondero 3" y "Rondero 4", me han torturado varios días, aproximadamente 10, y me trasladaban de un lugar a otro en una camioneta al distrito de Ollachea, allí me amarraban de los testículos con una soga y también me amarraban de la cintura con soga y me tiraban de un barranco de unos 20 metros aproximadamente me soltaba hasta la mitad poco a poco y me tenían allí por unos 06 a 08 minutos ello ha pasado unas 4 veces aproximadamente, en otras ocasiones me arrojaban a un rio desnudo donde me amarraban de la cadera y mis manos y pies cuando me lanzaban al rio me decían "que muera este asesino" y también cuando me sacaban me hacían echar encima de unas espinas (huaraco) las mujeres traían eso por orden de "Rondero 1" ello habrá pasado unas 03 veces aproximadamente, y me echaban, me pisaban y luego me levantaban y preguntaban quiénes eran mis cómplices y a quienes más había matado... otro día en Macusani en horas de la madrugada "Rondero 2" y sus compañeros me ha llevado en la camioneta de serenazgo a eso de las 01:00 a 02:00 de la madrugada aproximadamente, al lugar denominado Chichani y me lanzaron a una laguna desnudo y me dijeron que <este asesino que se muera hay que desaparecerlo> yo me encontraba casi inconsciente sin dormir, me sentía en con sueño y también me daban golpes, y entre varios me golpeaban y me hacían echarme en la nevada, luego me hicieron regresar a Macusani, al regresar a Macusani 3 Ronderos me esperaban para torturarme metiéndome a un cilindro de agua con detergente, al mismo tiempo me golpeaban con un palo... otro día los ronderos comenzaron a gritar y a azuzar diciendo lo quemamos lo quemamos, allí nuevamente me quitaron la ropa y me llevaron al rio caminando donde pese a que estaba nevando me metieron al rio y me amarraron con una soga, me metían y me sacaban del rio, me sacaron me hacían poner de rodillas en la nieve desnudo y así hasta el amanecer, llegando al local de la ronda en el día me quitaban la ropa y me echaban con agua (...), luego me llevaron al local de las Rondas Campesinas del Barrio Héroes del Cenepa donde me seguían torturando y la persona de Rondero 1 y Rondero 2 me pasaron dos cables de electricidad los cuales me ponían en la mano y me hacían pasar electricidad hasta que quede inconsciente y tirado en el suelo, y me querían quitar la vida, esa noche los de la ronda tuvieron una reunión donde acordaron entregarme a los Ronderos de Ayapata y no a la Fiscalía...(...)". 
De similar forma se tiene extractos de la manifestación a nivel fiscal de "denunciante 2" quien indica lo siguiente: “(...) ¿cuál sería la participación de cada una de las personas que ha denunciado por los delitos de secuestro, tortura y coacción, indique denunciado por denunciado? Habría respondido: (...) La persona de "Rondero 1" ... ha ordenado en mi presencia a los hermanos "Rondero 5, "Rondero 6" y "Rondero 7" que me torturen, les daba las órdenes de cómo, dónde y de qué manera tenían que torturame, les ordenaba llevarme al rio, colgarme de los testículos, ordenó que me hagan pasar cadena ronderil por las 19 bases de la provincia de Carabaya, en 19 días he terminado la cadena ronderil, en cada base me castigaban de distinta manera; así también esta persona ha ordenado que me capturen y me retengan por más de 30 días hasta que acepte que yo había matado, violado a la persona de "X", así también en el local de las Rondas Campesinas del distrito de Macusani la persona de "Rondero 1" me ha torturado personalmente, me desnudaba me golpeaba, me colgaba de los testículos, así también me hacía poner de cabeza al suelo, donde ponían cascajo y ortiga por el lapso de 40 a 50 minutos desnudo, eso se llama chinche, me hacían hacer ranas, planchas, marcha patitos, esa torturas que me hizo directamente duraron aproximadamente 02 semanas, luego de lo cual ordenó que me llevaran a las diferentes bases de la Ronda campesina. (...) yo le he dicho que tenga compasión y me entregue al Ministerio Público; y me dijo que para que te vamos a entregar al Ministerio Público si también son igual que tú y manejan la ley ordinaria, nosotros manejamos la costumbre y te vamos a juzgar con los usos y costumbres y yo estaba desnudo amarrado en el piso, y les pedí que no me mataran ni quemaran por mis hijitos, porque soy viudo. Respecto a las torturas ellos en el local de la base de Héroes del Cenepa durante unos 05 a 06 días antes de que me entreguen al Ministerio Publico los hermanos Ronderos 5, Rondero 6 y Rondero 7 me han metido en un cilindro de agua tibia desnudo, con las manos amarradas atrás y luego me curaban una semana antes de entregarme al Ministerio Publico con frotaciones, con yerbas molidas me parchaban me curaban mis cicatrices de mi cuerpo, así también lavaron mi ropa para que me entreguen al fiscal, así mismo dijeron que mejor lo entregamos al barrio Santa Sabina del distrito de Macusani por que van a decir que lo hemos tenido mucho tiempo en la base Héroes del Cenepa y me entregaron el día 15 de Setiembre de 2015. (...)”.

\section{3.- Análisis objetivo de las actuaciones.-}

De estos dos extractos de la declaración de los denunciantes y de las entrevistas realizadas a diferentes autoridades del gobierno local y de entrevista a varios profesionales que labora en dicha provincia quienes en su mayoría son foráneos y ven de alguna u otra manera sin subjetividades el actuar de las Rondas Campesinas de dicho distrito, se efectúa el análisis siguiente, en principio las Rondas Campesinas de dicho distrito actúan en la creencia que tienen jurisdicción y competencia para administrar justicia olvidando que la facultad que les concede la norma constitucional es de apoyo a las autoridades comunales en su función jurisdiccional, ahora bien al realizar entrevistas a estos miembros de las Rondas Campesinas ellos invocan que actúan de esa manera porque les faculta el artículo 149 de la constitución y los alcances del acuerdo plenario Plenario 1-2009/ CJ-116, sin embargo verificando dicha norma y jurisprudencia se tiene que estas fuentes orientan la actuación de la organización de la Rondas Campesinas donde claramente especifican que su intervención en la Justicia comunitaria tiene que ser un órgano de apoyo a las autoridades de una comunidad campesina quienes si tienen jurisdicción; es decir la labor de un miembro de las Rondas Campesinas en la Justicia comunitaria es de apoyo y colaboración como un auxiliar a la autoridad comunal, esta autoridad puede ser el presidente de la Comunidad Campesina o el Juez de Paz No Letrado quien este último cumple la labor de administrar justicia conciliatoria en una Comunidad Campesina o Nativa o centros poblados conforme la Ley Orgánica del Poder Judicial esto en lugares remotas donde no exista presencia del Estado como Poder Judicial que administra Justicia ordinaria; entonces de los casos que se expusieron se tiene que algunos miembros de las rondas campesinas del distrito de Macusani actúan en una equivoca creencia de tener jurisdicción y competencia y lo peor de todo en un medio urbano, pues conforme la norma constitucional citada su labor es netamente de apoyo a la autoridad comunal quien este último si contaría con competencia para realizar labores jurisdiccionales utilizando el derecho consuetudinario en un medio rural; pero más no un miembro 
de la ronda, quien más bien debe apoyar en dicha labor de administrar justicia comunitaria a la autoridad comunal.

Ahora bien como segundo irregularidad se tiene que la norma constitucional y el acuerdo plenario son expresas preestablecen que sus actuaciones tanto de las rondas campesinas como de las autoridades comunales deben desenvolverse dentro de su ámbito territorial, y esta debe entenderse como el medio rural "Comunidad Campesina o nativa"; sin embargo de los casos expuestos se tiene que las Rondas Campesinas en el distrito de Macusani actúan y se desenvuelven dentro de la ciudad teniendo como base de operaciones un barrio así se tiene la Ronda Campesina del Barrio Túpac Amaru, Ronda Campesina del Barrio Héroes del Cenepa, Ronda Campesina del Barrio Jorge Chávez, Ronda Campesina del Barrio Simón Bolívar y Rondas Campesinas del Barrio Miraflores, si bien es cierto que existe la libertad de formar una organización con sede en cualquier parte del Perú; sin embargo cuando se trata de este tipo de organizaciones se debe tener en cuenta la competencia territorial en la que debe desenvolverse; así se tiene que una Ronda Campesina, tal y cual precisa su propia denominación debe tener su funcionamiento en un medio rural es decir fuera de un radio urbano; lo que no ocurre en este distrito de Macusani pues las Rondas Campesinas ejercen y se desenvuelven dentro de la ciudad teniendo como base de operaciones y funcionamiento un barrio de dicha ciudad, desnaturalizando de tal manera la justicia campesina o comunitaria.

Un tercer aspecto y la más principal es que las actuaciones de estos miembros de las Rondas Campesinas lo efectúan vulnerando derechos fundamentales, pues del caso se tiene que en muchas ocasiones los denunciantes han sido víctima de tortura hasta en algunos casos atentados contra su vida; a pesar que sean investigados por la presunta comisión de un delito aun así cuenta con sus derechos de carácter nuclear como la vida y la integridad física; entonces tenemos que no existe una adecuada actuación de las Rondas Campesinas a nivel general no solo en esta ciudad pues de los medios de comunicación y redes sociales también se ha encontrado casos similares en otras regiones del país; entonces colegimos de que el motivo por el cual actúan de esa manera las Rondas Campesinas no sería tanto desconocimiento del espirito de este artículo constitucional ni de la jurisprudencia sino se debe a que en nuestro sistema jurídico no existe la "Ley de coordinación jurisdiccional entre la justicia ordinaria y la justicia comunitaria" pues la norma del artículo $149^{\circ}$ expresa en su última parte que "La ley establece las formas de coordinación de dicha jurisdicción especial con los Juzgados de Paz"; sin embargo actualmente no existe dicha Ley de coordinación jurisdiccional que establezca combinación y estrechar enlaces entre la Justicia comunitaria con la justicia ordinaria por consiguiente existe una necesidad imperiosa de la emisión de la Ley de coordinación mencionada a fin de establecer lineamientos para la actuación de las autoridades comunales y de Rondas Campesinas, esto a través de una propuesta legislativa o en todo caso retomar nuevamente dicha discusión en el parlamento y su posterior aprobación y emisión en nuestro sistema jurídico peruano.

\section{4.- Necesidad de implementación de la Ley de coordinación jurisdiccional}

La jurisdicción a que hacemos mención tantas veces para administrar justicia comunal conforme el derecho consuetudinario es embestido a las autoridades comunales que en este caso puede ser el Juez de Paz, mas no directamente a un miembro de la Ronda Campesina, esta jurisdicción que les faculta la norma constitucional (Artículo $149^{\circ}$ ) a las autoridades comunales si bien les limita a realizar administración de justicia ordinaria y solo les faculta efectuar justicia de carácter conciliatorio con el uso del derecho consuetudinario; sin embargo conforme la Ley orgánica del Poder Judicial les faculta a los Jueces de Paz otras funciones como el de notarial y administrar justicia en procesos de carácter de menor cuantía como proceso de alimentos, cobros de dinero, interdictos entre otros. (Artículo 65 de la LOPJ); entonces verificamos que existe una colisión de normas en este caso una norma de rango inferior que es una Ley Orgánica contra la norma constitucional; por lo que a fin de evitar este tipo de colisiones y a fin de uniformizar las normas que regulan una Justicia Comunal se debe de plantear nuevamente a través de una propuesta legislativa la emisión de la "Ley de coordinación jurisdiccional entre la justicia ordinaria y la justicia comunitaria”; y así de una vez por todas existiría el estrecho y enlace entre la Justicia ordinaria con la Justicia extraordinaria especial comunal, pues no solo en Macusani existe 
actuaciones inadecuadas al momento de poner en practica la Justicia comunal sino a nivel nacional, pues al no existir un reglamento o ley especial que regule las funciones y competencias de las autoridades comunales y de las Rondas Campesinas se comenten involuntariamente atropellos a los derechos fundamentales como las que se han planteado líneas arriba o en muchas ocasiones no actúan dentro del ámbito territorial para las que le son facultadas, por lo que existe una necesidad urgente de la emisión de la Ley de coordinación jurisdiccional entre la justicia ordinaria y la justicia comunitaria en nuestro sistema jurídico peruano.

\section{III.- CONCLUSIÓN}

Existe la necesidad urgente de que en nuestro ordenamiento jurídico peruano se emita la "Ley de coordinación jurisdiccional entre la justicia ordinaria y la justicia comunitaria" donde se especifique las facultades, funciones y reglas para el funcionamiento de la Justicia comunal como una forma especial de administración de justicia en las comunidades campesinas y nativas donde no llega la justicia ordinaria; ya que al no existir dicha Ley los miembros de las Rondas Campesinas y las autoridades comunales realizan inadecuada actuación y en muchas ocasiones hasta vulnerando derechos fundamentales como las que se ha ilustrado en el presente artículo, de tal forma que al tener parámetros definidos existiría armonía entre la Justicia ordinaria y la justicia comunitaria.

\section{REFERENCIA BIBLIOGRÁFICA}

BADENI, G. (2006). Tratado de Derecho Constitucional. Segunda edición. Tomo I. Editorial La Ley, Buenos Aires, Argentina.

LEDESMA M. (2008). Comentarios al Código Procesal Civil, Tomo I. Gaceta Jurídica. Lima, Peru.

LINARES, S. (1953). Reglas para le interpretación constitucional. EU, Plus Ultra, Buenos Aires, Argentina.

PEREZ, A. (1995). Los derechos fundamentales, $6^{a}$ edición. Editorial Técnos S.A., Madrid.

MONROY J. (1996). Introducción al proceso civil. Temis. Santa Fe de Bogotá.

RUBIO, M. (1999). Estudio de la constitución política de 1993. Tomo VI. Fondo Editorial, Lima, Perú.

Sagüés, N. (2007). Manual de Derecho Constitucional. Editorial Astrea. Buenos Aires, Argentina.

SALMON, E. (2012). La Consulta Previa, libre e informada en el Perú. Biblioteca Nacional del Perú. Lima:

YRIGOYEN, R. (1995). Constitución, Jurisdicción Indígena y Derecho Consuetudinario. PUCP Lima

YRIGOYEN, R. (2002) Justicia Comunitaria en los Andes. Revista Alpanchis: No 59-60 Edición Especial, Vol. 1. Sicuani, Cusco. 